\title{
Trends in use of neonatal CPAP: a population-based study
}

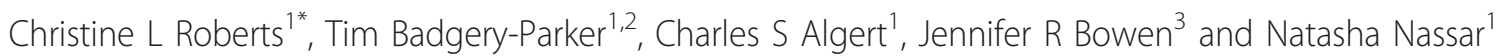

\begin{abstract}
Background: Continuous positive airway pressure (CPAP) is used widely to provide respiratory support for neonates, and is often the first treatment choice in tertiary centres. Recent trials have demonstrated that CPAP reduces need for intubation and ventilation for infants born at 25-28 weeks gestation, and at > 32weeks, in nontertiary hospitals, CPAP reduces need for transfer to NICU. The aim of this study was to examine recent population trends in the use of neonatal continuous positive airway pressure.

Methods: We undertook a population-based cohort study of all 696,816 liveborn neonates $\geq 24$ weeks gestation in New South Wales (NSW) Australia, 2001-2008. Data were obtained from linked birth and hospitalizations records, including neonatal transfers. The primary outcome was CPAP without mechanical ventilation (via endotracheal intubation) between birth and discharge from the hospital system. Analyses were stratified by age $\leq 32$ and $>32$ weeks gestation.

Results: Neonates receiving any ventilatory support increased from 1,480 (17.9/1000) in 2001 to 2,486 (26.9/1000) in 2008, including $461(5.6 / 1000)$ to 1,465 (15.8/1000) neonates who received CPAP alone. There was a concurrent decrease in mechanical ventilation use from 12.3 to 11.0/1000. The increase in CPAP use was greater among neonates $>32$ weeks (from 3.2 to 11.8/1000) compared with neonates $\leq 32$ weeks (from 18.1 to 32.7/1000). The proportion of CPAP > 32 weeks initiated in non-tertiary hospitals increased from 6\% to $30 \%$.

Conclusions: The use of neonatal CPAP is increasing, especially $>32$ weeks gestation and among non-tertiary hospitals. Recommendations are required regarding which infants should be considered for CPAP, resources necessary for a unit to offer CPAP and monitoring of longer term outcomes.
\end{abstract}

\section{Background}

Continuous positive airway pressure (CPAP) is used widely to provide respiratory support for neonates, and is often the first treatment choice in tertiary centres [1,2]. There are multiple ways of providing CPAP (eg via underwater bubble CPAP, flow driver or ventilator), different patient interfaces (eg binasal prongs, a single nasopharyngeal prong, face mask, high flow nasal cannula) and various levels of water pressure may be used (usually 4-8 cm water). For extremely preterm neonates, CPAP is an alternative to intubation and mechanical ventilation [3] and at later gestational ages, CPAP may be an alternative to

\footnotetext{
* Correspondence: clroberts@med.usyd.edu.au

${ }^{1}$ Clinical and Population Perinatal Health Research, Kolling Institute of Medical Research, University of Sydney, Department of Obstetrics \& Gynaecology, Level 2, Building 52, Royal North Shore Hospital, St Leonards, NSW, 2065, Australia

Full list of author information is available at the end of the article
}

headbox oxygen therapy [4]. CPAP is an attractive option for supporting neonates with respiratory distress, because it preserves spontaneous breathing, does not require endotracheal intubation, and may result in less lung injury than mechanical ventilation [2]. Older and larger neonates appear to be managed effectively using CPAP as the initial and primary method for support without the need for surfactant [1]. However, a significant proportion of neonates born very preterm, particularly prior to 28 weeks, may require combinations of respiratory support modes, which could include surfactant treatment, endotracheal intubation and mechanical ventilation and/or CPAP.

Until recently, there was a lack of data from randomized controlled trials (RCTs) on the effectiveness of CPAP [4,5]. Between 2002 and 2006, Buckmaster and colleagues conducted an RCT comparing CPAP with headbox oxygen for neonates $>31$ weeks born in nontertiary hospitals and found CPAP reduced the need for
C Biomed Central

() 2011 Roberts et al; licensee BioMed Central Ltd. This is an Open Access article distributed under the terms of the Creative Commons Attribution License (http://creativecommons.org/licenses/by/2.0), which permits unrestricted use, distribution, and reproduction in any medium, provided the original work is properly cited. 
transfer to a neonatal intensive care unit (NICU) [6]. Trials in very preterm babies published since 2008 suggest that starting CPAP at birth may have important benefits, with $50 \%$ of babies $25-28$ weeks gestation never requiring intubation and ventilation, and that neonates of this gestational age who commence CPAP from birth have no increased risk of death or bronchopulmonary dysplasia, and in fact are less likely to be on oxygen at 28 days of age $[7,8]$.

Other potential advantages of CPAP compared with intubation and subsequent conventional mechanical ventilation include lower costs, easier operation, potentially fewer risks, and less training [1]. Nevertheless, CPAP is still considered resource-intensive, requiring skilled and experienced staff to ensure the success of the treatment [5] and may result in an increased risk of pneumothorax and nasal trauma $[6,8]$. The aim of this study was to use population data to examine statewide trends in CPAP use. An additional aim was to assess whether CPAP use changed in hospitals that participated in the Buckmaster CPAP trial [6].

\section{Methods}

\section{Study population}

The study population included all live births in New South Wales (NSW), Australia, from January 2001 to December 2008 with a gestational age of at least 24 weeks and for whom the birth record linked to at least one hospital record. Neonates transferred interstate within 7 days of birth $(N=585,<0.1 \%)$ were excluded because no further information was available for these neonates. New South Wales is the most populous state in Australia with a population of 7.2 million and over one-third of all Australian births [9].

\section{Data sources}

The data for this study were obtained from the NSW Midwives Data Collection (MDC) and the NSW Admitted Patient Data Collection (APDC). The MDC (referred to as 'birth' records) is a population-based surveillance system covering all livebirths and stillbirths in NSW. The information is recorded by either the midwife or medical practitioner attending the birth, and includes demographic, medical and obstetric information on the mother and information on the labour, delivery and condition of the neonate. The APDC (referred to as 'hospital' records) is a census of all inpatient admissions (public and private) in NSW. It includes a range of demographic data and clinical information. The diagnoses and procedures related to the admission are coded according to the 10th revision of the International Statistical Classification of Diseases and Related Health Problems, Australian Modification (ICD10-AM) and the affiliated Australian Classification of Health Interventions, respectively.
The birth record and the infant hospital record associated with the birth were linked for each neonate. Hospital records were also linked longitudinally to identify hospital-to-hospital transfers and readmissions. Probabilistic record linkage was conducted independent of the research by the NSW Centre for Health Record Linkage [10]. No health information is used for linkage, and at no time is identifying information made available to researchers. The study was approved by the NSW Population and Health Services Research Ethics Committee.

\section{Outcome and explanatory factors}

The primary outcome was whether a neonate received CPAP or mechanical ventilation (via endotracheal intubation) between birth and initial discharge from the hospital system, identified from any of 20 procedure fields in any of the neonate's hospital records. A NSW validation study found that any mechanical ventilation and CPAP are reliably reported in population health data [11]. For analysis, neonates were classified as 'ventilation' if they received mechanical ventilation, whether or not they received CPAP, and as 'CPAP' if they received CPAP alone and did not receive mechanical ventilation in the period from birth to discharge from the hospital system. Neonatal transfer to a NICU was a secondary outcome.

Hospitals were categorised as 'tertiary', 'CPAP trial' and 'other non-tertiary'. Tertiary hospitals $(n=7)$ have a Level III neonatal intensive care unit (NICU) which provides mechanical ventilation and care for neonates with severe and/or complex illness [12]. The CPAP trial hospitals were the five NSW hospitals that participated in the Buckmaster CPAP trial [6]. Participation in this trial required a paediatric registrar onsite 24-hours and nursing staff trained in use of CPAP for neonates. The 'other non-tertiary' hospitals $(\mathrm{n}=78)$ included all other public and private hospitals at which babies were born in NSW, and have service levels ranging from general practitioner or midwife care with low level neonatal care to special care nurseries. The neonatal factors available for analysis included gender, plurality (singleton vs multiple), gestational age, small for gestational age (SGA, $<10$ th percentile) and large for gestational age (LGA, $>$ 90th percentile), [13] Apgar score less than 4 at 1 minute and Apgar score less than 7 at 5 minutes. Gestational age is reported in completed weeks of gestation as determined by the best clinical estimate, including early ultrasound (> 97\%) and date of the last menstrual period. Only factors that are accurately reported were included in the analyses [14-18].

\section{Analysis}

We determined rates of CPAP over time and by neonate characteristics, gestational age and hospital of CPAP initiation. Gestational age was categorised as $\leq 32$ weeks 
and $>32$ weeks, based on national policy recommending neonates $\leq 32$ weeks be delivered in tertiary centres [19].

\section{Results}

The study included 696,816 live births of at least 24 weeks gestation born in NSW between 2001 and 2008, increasing from 82,542 in 2001 to 92,461 in 2008. Of all infants, $191,511(27.5 \%)$ were born at tertiary hospitals, 94,390 $(13.5 \%)$ at CPAP-trial hospitals and 410,915 (59.0\%) at other non-tertiary hospitals. Overall 6,188 (8.9/1000 livebirths) neonates received CPAP alone and 8,229 (11.8/ $1000)$ received mechanical ventilation with or without CPAP, including 3,700 (5.3/1000) who received both mechanical ventilation and CPAP. Compared to neonates who did not receive any ventilatory support, those receiving CPAP alone were more likely to be male (59\% versus $51 \%)$, of multi-fetal pregnancies (21\% versus $3 \%)$, born at $<37$ weeks (69\% versus 5\%) and have low Apgar scores at 1 (10\% versus $2 \%$ ) and/or 5 minutes (9\% versus $1 \%$ ) (Table 1 ). Twins and triplets were 8.6 times more likely than singletons to receive CPAP alone, but after adjusting for gestational age this risk decreased substantially (adjusted RR: 1.13; 95\% CI: 1.07-1.20). For the gestational ages 31 through 36 weeks, more neonates received CPAP alone than were ventilated. Ventilation numbers only exceeded CPAP alone at $\leq 30$ weeks gestation (Table 1 ). The gestation-specific rates of CPAP alone were 261.9/1000 among neonates $\leq 32$ weeks, $51.3 / 1000$ at 33-36 weeks and 2.9/ 1000 at $\geq 37$ weeks. Among infants who required respiratory support, those with transient tachypnea were more than twice as likely to be managed with CPAP alone $(\mathrm{RR}=$ 2.5; 95\% CI 2.3-2.7) compared to those with other diagnoses; $65 \%$ of infants with transient tachypnea as one of their admitting diagnoses and requiring respiratory support received CPAP alone.

The number and rate of neonates receiving any ventilatory support increased from 1,480 (17.9/1000) in 2001 to $2,486(26.9 / 1000)$ in $2008(\mathrm{P}<0.001)$, including an increase from $461(5.6 / 1000)$ to $1,465(15.8 / 1000)$ neonates who received CPAP alone $(\mathrm{P}<0.001)$ (Figure 1$)$. There was a concurrent decrease in any use of mechanical ventilation from 12.3 to $11.0 / 1000$ livebirths. However, there was no significant change in the use of combined mechanical ventilation and CPAP $(\mathrm{P}=0.52)$. The relative increase in the use of CPAP alone was greater among neonates $>32$ weeks (increasing 3.7 -fold from $3.2 / 1000$ in 2001 to $11.8 / 1000$ livebirths in 2008) compared with neonates aged $\leq 32$ weeks (increasing 1.8-fold from 18.1 to 32.7/1000 livebirths) (Figure 2).

When examined by hospital of initiation, $89 \%$ of CPAP was initiated in tertiary centres, including $8 \%$ that was initiated following neonatal transfer. Although in absolute numbers CPAP initiated in tertiary centres among neonates $>32$ weeks increased, the proportion provided by tertiary hospitals declined from $94 \%(3.0 / 1000)$ in 2001 to $70 \%(8.3 / 1000)$ in 2008 ( $<<0.001$, Figure 3$)$. Compared with 2003-2006 (the period of Buckmaster trial), the number of neonates $>32$ weeks receiving CPAP alone at the CPAP trial hospitals doubled in 2007. From 2001 to 2006, between 3 (2.5\%) and 11 (9.6\%) other non-tertiary hospitals provided CPAP to neonates (Figure $3)$. In 2007, this number had doubled, with 22 (23.4\%) hospitals providing CPAP to 56 neonates, and by 2008 further increased to 27 hospitals (28.1\%) treating 222 infants. From 2001 to 2008, the proportion of neonates born outside a tertiary centre and transferred to a NICU declined slightly from $755(1.2 \%)$ to $745(1.1 \% \mathrm{P}<0.001)$. Neonates who received CPAP at the CPAP trial hospitals were significantly less likely to be transferred to a NICU than neonates who received CPAP at other non-tertiary hospitals $(13.6 \%$ versus $20.1 \%, \mathrm{P}=0.03)$.

\section{Discussion}

Use of CPAP without mechanical ventilation for neonates increased from 2001 to 2008, with a particularly notable rise among infants of $>32$ weeks gestation and at non-tertiary hospitals in 2008. Although the rates of CPAP use were highest among infants $\leq 30$ weeks, in terms of absolute numbers of neonates exposed, the burden was higher among more mature neonates. The relatively slower increase in CPAP use among neonates $\leq 32$ weeks may relate to greater difficulty in supporting very premature neonates on CPAP alone without a period of mechanical ventilation or may reflect the lack of evidence regarding use of CPAP in very preterm neonates available during the study period. Trials in very preterm neonates published from 2008 support the consideration of CPAP as an alternative to intubation and surfactant, $[7,8]$ and as these findings are translated into practice we may see a further increase in CPAP rates.

CPAP use among neonates $>32$ weeks increased slowly from 2001 through 2004, followed by greater increases, particularly in 2008. During this period, there was no increase in the temporal trend of births $\leq 32$ or $>32$ weeks gestation. The overall increase in neonates receiving CPAP was offset by a small decrease in rate of mechanical ventilation, resulting in a significant increase in total number of infants receiving ventilatory support (CPAP or mechanical ventilation). This suggests that the increase was primarily due to an increase in CPAP in neonates who would previously have received only supplemental oxygen in either a tertiary or non-tertiary unit. The 2007 increase coincided with publication of the Buckmaster CPAP trial results, which showed CPAP for selected neonates at appropriately resourced non-tertiary hospitals could reduce transfers to a NICU [6]. At the hospitals involved in the CPAP trial the number of neonates receiving CPAP doubled after the trial, implying 
Table 1 Characteristics of neonates receiving CPAP or mechanical ventilation, NSW 2001-2008

\begin{tabular}{|c|c|c|c|c|c|c|}
\hline Infant and hospital characteristics & \multicolumn{2}{|c|}{$\begin{array}{l}\text { CPAP alone } \\
\mathrm{N}=6188\end{array}$} & \multicolumn{2}{|c|}{$\begin{array}{l}\text { Mechanical ventilation* } \\
\qquad \mathrm{N}=8229\end{array}$} & \multicolumn{2}{|c|}{$\begin{array}{c}\text { No ventilation or CPAP } \\
\qquad N=682,399\end{array}$} \\
\hline Male & 3625 & $(58.6)$ & 4908 & $(59.6)$ & 350346 & $(51.3)$ \\
\hline Female & 2563 & $(41.4)$ & 3321 & $(40.4)$ & 332053 & $(48.7)$ \\
\hline Singleton & 4870 & $(78.7)$ & 6846 & $(83.2)$ & 663798 & $(97.3)$ \\
\hline Multiple & 1318 & $(21.3)$ & 1383 & $(16.8)$ & 18601 & $(2.7)$ \\
\hline \multicolumn{7}{|l|}{ Gestational age } \\
\hline $24-26$ & 80 & $(1.3)$ & 1008 & $(12.3)$ & 207 & $(0.03)$ \\
\hline $27-29$ & 559 & $(9.0)$ & 1506 & $(18.3)$ & 276 & $(0.04)$ \\
\hline 30-32 & 1734 & $(28.0)$ & 1355 & $(16.5)$ & 2337 & $(0.3)$ \\
\hline 33-34 & 1115 & $(18.0)$ & 803 & $(9.8)$ & 7598 & $(1.1)$ \\
\hline 35-36 & 800 & $(12.9)$ & 682 & $(8.3)$ & 26332 & (3.9) \\
\hline $37-38$ & 681 & $(11.0)$ & 995 & $(12.1)$ & 151713 & $(22.2)$ \\
\hline $39-40$ & 803 & (13.0) & 1282 & $(15.6)$ & 371034 & $(54.4)$ \\
\hline $41-42$ & 413 & $(6.7)$ & 597 & $(7.3)$ & 122056 & $(17.9)$ \\
\hline$>42$ & 3 & $(0.05)$ & 1 & $(0.01)$ & 846 & $(0.12)$ \\
\hline \multicolumn{7}{|l|}{ Size at birth } \\
\hline$<10$ th centile & 636 & $(10.3)$ & 1127 & $(13.7)$ & 64996 & $(9.5)$ \\
\hline 10th-90th centile & 4865 & (78.6) & 6241 & $(75.8)$ & 545275 & $(79.9)$ \\
\hline > 90th centile & 687 & $(11.1)$ & 861 & $(10.5)$ & 72128 & $(10.6)$ \\
\hline \multicolumn{7}{|l|}{ Apgar at 1 minute } \\
\hline$<4$ & 626 & $(10.2)$ & 2450 & $(30.1)$ & 10011 & $(1.5)$ \\
\hline$\geq 4$ & 5538 & (89.8) & 5701 & $(69.9)$ & 670734 & $(98.5)$ \\
\hline \multicolumn{7}{|l|}{ Apgar at 5 minutes } \\
\hline$<7$ & 529 & (8.6) & 2375 & $(29.1)$ & 6355 & $(0.9)$ \\
\hline$\geq 7$ & 5634 & (91.4) & 5783 & (70.9) & 674538 & $(99.1)$ \\
\hline
\end{tabular}

* with or without CPAP

that neonates who would previously have been randomized to oxygen were instead being given CPAP.

The use of large, linked, validated population-based databases that provide information on all neonates is a strength of this study. However, these data do not have detailed clinical information such as the severity of disease, use of surfactant or the duration of CPAP. Furthermore, the temporal sequence of events (eg CPAP, mechanical ventilation, pneumothorax) cannot be determined, only that the events occurred during an admission. This limits the ability to assess complications or reasons for changes in the respiratory support methods.

Nasal CPAP has been adopted by many NICUs as a way of reducing rates of bronchopulmonary dysplasia in premature neonates, but assessment of its benefits is complicated by questions about the simultaneous effects of concomitant surfactant treatments and other NICU interventions [20]. Most research into the potential benefit of CPAP has used a study population of very preterm or extremely preterm neonates who were delivered in tertiary referral hospitals. Little is known about the benefits of CPAP use in more mature neonates in tertiary NICUs. The Buckmaster trial compared CPAP use with supplemental oxygen in neonates $>30$ weeks gestation in non-tertiary centres [6] to prevent transfer of neonates for intensive care. The study showed a reduction in both treatment 'failure' $(\mathrm{RR}=0.54 ; 95 \% \mathrm{CI} 0.32,0.91)$ and the rate of up-transfer $(\mathrm{RR}=0.51 ; 95 \% \mathrm{CI} 0.31,0.89)$, but did not show any statistically significant reduction in outcomes such as length of admission. The results also show an increased risk of pneumothorax in the CPAP arm but the confidence interval is wide $(R R=2.76 ; 95 \%$ CI 1.02 , 7.48). The possibility of increased rates of pneumothorax has been a concern with use of CPAP, and the COIN trial [8] reported a rate of pneumothorax three times higher in the CPAP group compared with the mechanical 


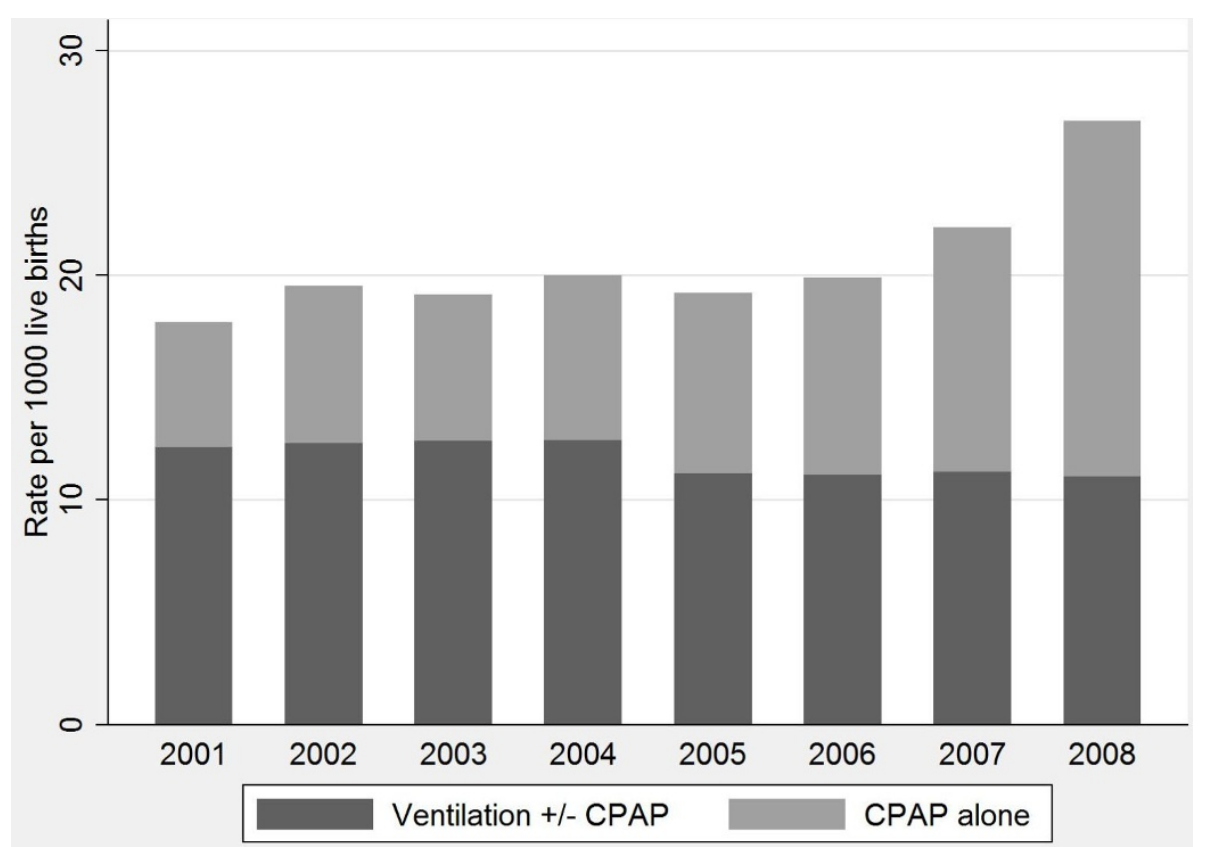

Figure 1 Trend in ventilation and CPAP rates among neonates, NSW 2001-2008

ventilation group. However, the recently published results of the SUPPORT trial found no difference in the rates of pneumothorax for extremely preterm neonates randomized to initial treatment with either CPAP or endotracheal administration of surfactant [7]. Further, the long term consequences of CPAP remain undetermined and need to be monitored.
Although our findings highlight that most neonates treated with CPAP are cared for in tertiary centres, there was an increase in the proportion treated outside these hospitals. Our study found that most nontertiary non-CPAP-trial hospitals that provided CPAP support treated relatively few neonates in 2007-2008; and this may be inadequate to ensure safety and

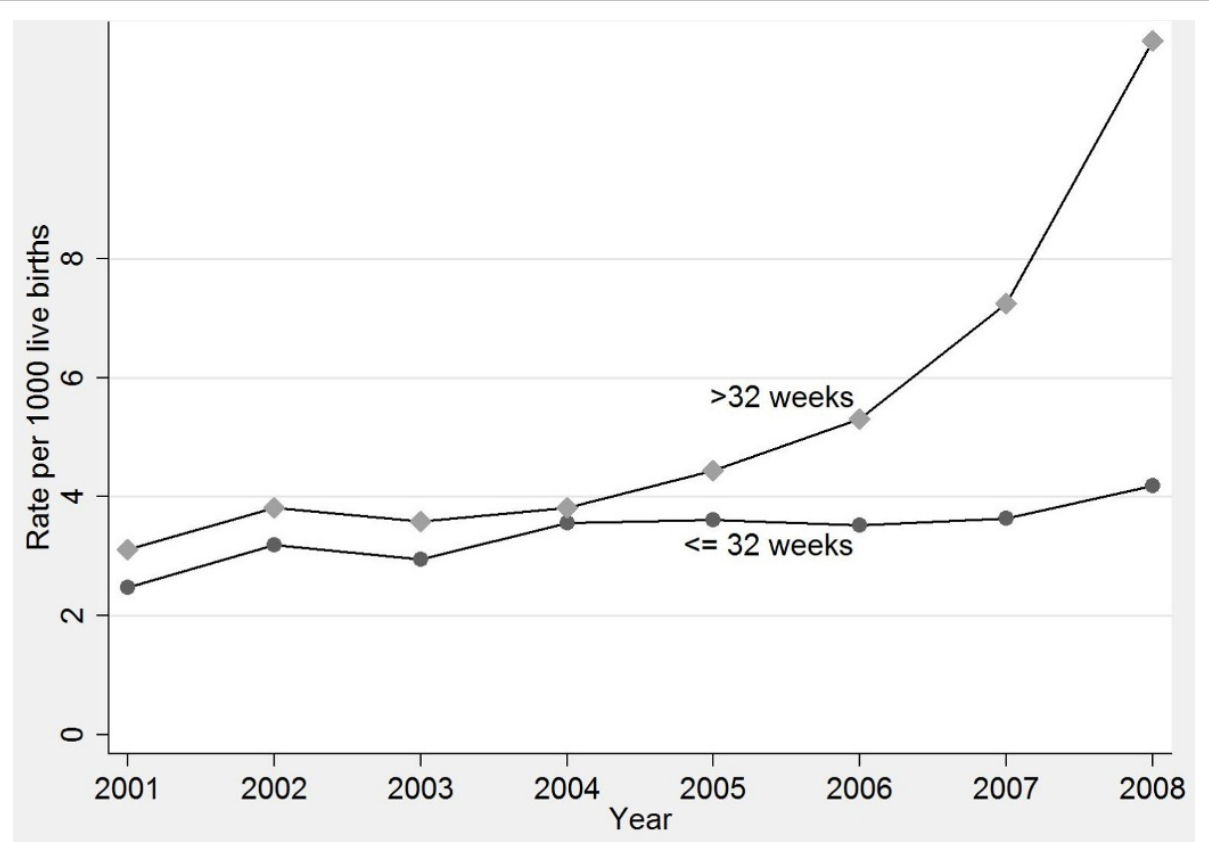

Figure 2 Trend in the CPAP rate per 1000 live births, by gestational age, NSW 2001-2008. 


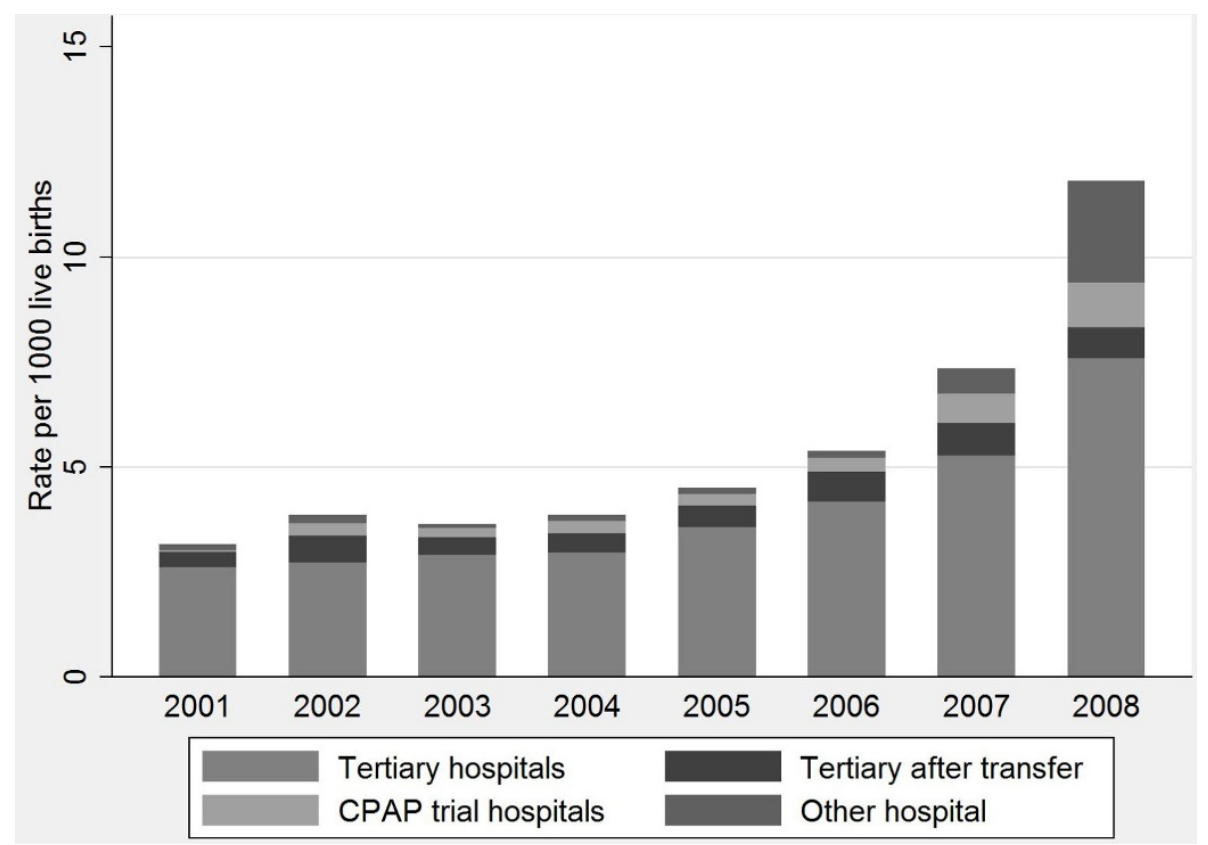

Figure 3 CPAP initiation for neonates $>32$ weeks by type of hospital.

cost-effectiveness of the intervention. CPAP is resource-intensive and caution has been advised with the use of CPAP in units that are not well staffed or experienced in its use [21-23]. Furthermore, it is important that the availability of CPAP facilities does not lead to complacency regarding policies of antenatal transfer of high risk pregnancies, particularly as in utero transfer has been demonstrated to be more beneficial and improve neonate outcomes [24].

Buckmaster estimated that on average, across an neonatal population, a cost saving of $\sim A U \$ 1,700$ would accrue for every neonate treated with CPAP [6]. However, increased use of CPAP is likely to increase costs at an individual hospital if additional resources, such as experienced staff and ongoing monitoring of CPAP neonates, are required [2]. Additional costs associated with CPAP use in non-tertiary hospitals may be offset by a reduction in neonatal transfers, decreased length of stay or better outcomes for neonates [24] and should be investigated. Although the Buckmaster CPAP trial did show a benefit in reduced transfers,[6] it is not known if this remains true in the wider group of hospitals now providing CPAP and among the potentially broader group of neonates exposed, especially given the small numbers treated at each hospital. Recommendations should be developed regarding which neonates should be considered for CPAP, and the appropriate resources necessary for a unit to offer CPAP. In addition, longer term outcomes for neonates who receive CPAP need to be monitored.

\section{Conclusions}

CPAP use has increased since 2001, most notably among neonates $>32$ weeks and this represents an extension of ventilatory support rather than replacement of mechanical ventilation. Furthermore, CPAP use appears to have increased in non-tertiary hospitals following publication of a randomized trial showing CPAP decreased the need for neonatal transfer. Our study highlights the need for recommendations about which neonates should be considered for CPAP and the appropriate resources necessary to offer CPAP.

\section{Abbreviations}

ACHI: Australian Classification of Health Interventions; APDC: NSW Admitted Patients Data Collection; CHeReL: Centre for Health Record Linkage; CPAP: continuous positive airway pressure; MDC: NSW Midwives Data Collection; NSW: New South Wales; SGA: Small for gestational age; LGA: Large for gestational age

\section{Acknowledgements}

We thank the NSW Department of Health for access to the population health data and the NSW Centre for Health Record Linkage for linking the data sets.

This work was funded by an Australian National Health and Medical Research Council (NHMRC) Project Grant (\#457302). Christine Roberts by a NHMRC Senior Research Fellowship (\#457078), Natasha Nassar by a NHMRC Career Development Award (\#632955) and Tim Badgery-Parker by a Partnership Grant (\#571451).

The NHMRC was not involved in the study design; the collection, analysis, and interpretation of data; the writing of the manuscript; or the decision to submit the manuscript for publication.

\section{Author details}

${ }^{1}$ Clinical and Population Perinatal Health Research, Kolling Institute of Medical Research, University of Sydney, Department of Obstetrics \& 
Gynaecology, Level 2, Building 52, Royal North Shore Hospital, St Leonards, NSW, 2065, Australia. ${ }^{2}$ NSW Department of Health, North Sydney, Australia. ${ }^{3}$ Department of Neonatology, Royal North Shore Hospital, Sydney, Australia.

\section{Authors' contributions}

Christine Roberts, Charles Algert and Natasha Nassar developed the concept and design of the study and were responsible for overall drafting of the manuscript. Tim Badgery-Parker conducted the analysis and drafted the methods and results. Jennifer Bowen revised the manuscript for important intellectual content. All authors contributed to the interpretation of data and had final approval of the manuscript to be published.

\section{Competing interests}

The authors declare that they have no competing interests.

Received: 5 July 2011 Accepted: 17 October 2011

Published: 17 October 2011

\section{References}

1. Diblasi RM: Nasal continuous positive airway pressure (CPAP) for the respiratory care of the newborn infant. Respir Care 2009, 54:1209-1235.

2. Sweet D, Bevilacqua G, Carnielli V, Greisen G, Plavka R, Saugstad OD, Simeoni U, Speer CP, Valls ISA, Halliday H: European consensus guidelines on the management of neonatal respiratory distress syndrome. $J$ Perinat Med 2007, 35:175-186.

3. Sweet DG, Carnielli V, Greisen G, Hallman M, Ozek E, Plavka R, Saugstad OD, Simeoni U, Speer CP, Halliday HL, European Association of Perinatal M: European consensus guidelines on the management of neonatal respiratory distress syndrome in preterm infants - 2010 update. Neonatology 2010, 97:402-417.

4. Halamek LP, Morley C: Continuous positive airway pressure during neonatal resuscitation. Clin Perinatol 2006, 33:83-98, vii.

5. Bohlin K, Jonsson B, Gustafsson AS, Blennow M: Continuous positive airway pressure and surfactant. Neonatology 2008, 93:309-315.

6. Buckmaster AG, Arnolda G, Wright IM, Foster JP, Henderson-Smart DJ: Continuous positive airway pressure therapy for infants with respiratory distress in non tertiary care centers: a randomized, controlled trial. Pediatrics 2007, 120:509-518.

7. Finer NN, Carlo WA, Walsh MC, Rich W, Gantz MG, Laptook AR, Yoder BA, Faix RG, Das A, Poole WK, et al: Early CPAP versus surfactant in extremely preterm infants. N Engl J Med 2010, 362:1970-1979.

8. Morley CJ, Davis PG, Doyle LW, Brion LP, Hascoet JM, Carlin JB: Nasal CPAP or intubation at birth for very preterm infants. N Engl J Med 2008, 358:700-708.

9. Australian Bureau of Statistics: Australian demographic statistics Canberra; 2009.

10. NSW Centre for Health Record Linkage. [http://www.cherel.org.au/, Accessed Sept 2010.

11. Ford JB, Roberts CL, Algert CS, Bowen JR, Bajuk B, Henderson-Smart DJ, group N, Ford JB, Roberts CL, Algert CS, et al: Using hospital discharge data for determining neonatal morbidity and mortality: a validation study. BMC Health Services Research 2007, 7:188.

12. Stark AR: Levels of neonatal care. Pediatrics 2004, 114:1341-1347.

13. Roberts $C L$, Lancaster PA: Australian national birthweight percentiles by gestational age. Med J Aust 1999, 170:114-118.

14. Roberts $\mathrm{CL}$, Bell JC, Ford JB, Morris JM: Monitoring the quality of maternity care: how well are labour and delivery events reported in population health data? Paediatr Perinat Epidemiol 2009, 23:144-152.

15. Taylor LK, Pym M, Bajuk B, Sutton L, Travis S, Banks C: Validation study: NSW Midwives Data Collection 1998 2000, 97-99.

16. Roberts CL, Bell JC, Ford JB, Hadfield RM, Algert CS, Morris JM: The accuracy of reporting of the hypertensive disorders of pregnancy in population health data. Hypertens Pregnancy 2008, 27:285-297.

17. Lain SJ, Roberts $C L$, Hadfield RM, Bell JC, Morris JM: How accurate is the reporting of obstetric haemorrhage in hospital discharge data? A validation study. Aust N Z J Obstet Gynaecol 2008, 48:481-484.

18. Bell JC, Ford JB, Cameron CA, Roberts CL: The accuracy of population health data for monitoring trends and outcomes among women with diabetes in pregnancy. Diabetes Res Clin Pract 2008, 81:105-109.

19. NHMRC: Clinical practice guidelines: care around preterm birth Canberra; 1997.
20. Patel D, Greenough A: Does nasal CPAP reduce bronchopulmonary dysplasia (BPD)? Acta Paediatr 2008, 97:1314-1317.

21. Department of Health Western Australia: Framework for the care of neonates in Western Australia Perth; 2009.

22. Neonatal Services Advisory Committee: Administration of nasal CPAP in nontertiary Level 2 nurseries Melbourne; 2003.

23. Queensland Health: Statewide Maternity and Neonatal Clinical Guidelines Program. Management of neonatal respiratory distress incorporating the administration of continuous positive airway pressure (CPAP). Document: NN0906.3-V2R11 Brisbane; 2009.

24. Bowman E, Doyle LW, Murton LJ, Roy RN, Kitchen WH: Increased mortality of preterm infants transferred between tertiary perinatal centres. BMJ 1988, 297:1098-1100

\section{Pre-publication history}

The pre-publication history for this paper can be accessed here: http://www.biomedcentral.com/1471-2431/11/89/prepub

doi:10.1186/1471-2431-11-89

Cite this article as: Roberts et al:: Trends in use of neonatal CPAP: a population-based study. BMC Pediatrics 2011 11:89.

\section{Submit your next manuscript to BioMed Central and take full advantage of:}

- Convenient online submission

- Thorough peer review

- No space constraints or color figure charges

- Immediate publication on acceptance

- Inclusion in PubMed, CAS, Scopus and Google Scholar

- Research which is freely available for redistribution

Submit your manuscript at www.biomedcentral.com/submit
Ciomed Central 